\title{
Variable-Frequency Grid-Sequence Detector Based on a Quasi-Ideal Low-Pass Filter Stage and a Phase-Locked Loop
}

\author{
Eider Robles, Salvador Ceballos, Josep Pou, Member, IEEE, José Luis Martín, Member, IEEE, \\ Jordi Zaragoza, Student Member, IEEE, and Pedro Ibañez, Member, IEEE
}

\begin{abstract}
This paper proposes a filtered-sequence phase-locked loop (FSPLL) structure for detection of the positive sequence in three-phase systems. The structure includes the use of the Park transformation and moving average filters (MAF). Performance of the MAF is mathematically analyzed and represented in Bode diagrams. The analysis allows a proper selection of the window width of the optimal filter for its application in the $d q$ transformed variables. The proposed detector structure allows fast detection of the grid voltage positive sequence (within one grid voltage cycle). The MAF eliminates completely any oscillation multiple of the frequency for which it is designed; thus, this algorithm is not affected by the presence of imbalances or harmonics in the electrical grid. Furthermore, the PLL includes a simple-frequency detector that makes frequency adaptive the frequency depending blocks. This guarantees the proper operation of the FSPLL under large frequency changes. The performance of the entire PLL-based detector is verified through simulation and experiment. It shows very good performance under several extreme grid voltage conditions.
\end{abstract}

Index Terms-Frequency detection, grid-connected converters, moving average filter (MAF), phase-locked loop (PLL), sequence detector.

\section{INTRODUCTION}

$\mathbf{G}$ RID-SEQUENCE detection and synchronization is an issue of vital importance, especially under unbalanced and distorted conditions. This information is needed for the proper operation of grid-connected power electronic systems, such as power quality conditioners [1]-[4], distributed generation [5] and storage systems, uninterruptible power supplies (UPS), and flexible ac transmission systems (FACTS). Many synchronizing methods have been presented over the recent years. Some of these are based on a phase-locked loop (PLL)

Manuscript received October 16, 2009; revised January 4, 2010 and March 4, 2010; accepted April 27, 2010. Date of current version September 17, 2010. Recommended for publication by Associate Editor P. Mattavelli.

E. Robles, S. Ceballos, and P. Ibañez are with the Energy Unit, Tecnalia Technology Center, 48170 Zamudio, Spain (e-mail: erobles@ robotiker.es; sceballos@ robotiker.es; pedro@ robotiker.es).

J. Pou and J. Zaragoza are with the Terrassa Industrial Electronics Group, Department of Electronic Engineering, Technical University of Catalonia, 08222 Terrassa, Spain (e-mail: pou@eel.upc.edu; zaragoza@eel.upc.edu).

J. L. Martin is with the Department of Electronics and Telecommunications, University of the Basque Country, 48013 Bilbao, Spain (e-mail: joseluis.martin@ehu.es).

Color versions of one or more of the figures in this paper are available online at http://ieeexplore.iee.org.

Digital Object Identifier 10.1109/TPEL.2010.2050492 including a feedback loop with the purpose of controlling a magnitude, which is dependent on the voltage phase angle [6]-[11].

PLLs are possibly the most widely used synchronization methods in the case of grid-connected three-phase systems [12], [13]. The dynamic response of some methods, such as the one described in [14], is good under balanced grid voltages, but very slow when these are designed to operate under unbalanced or distorted grid voltages. The fast PLL method presented in [15] can cancel the influence of certain harmonics, however, the implementation of this method is highly complex and should be limited to canceling the effect of only a few harmonics. In [16], a novel control algorithm based on multiple reference frame theory is proposed to eliminate the low-order harmonic components in the ac currents of grid-tied converters when input ac voltages are unbalanced or contain low-order harmonics. The performance of the PLL-based synchronization method used in [17] is good, even under voltage imbalances and distortion. Nevertheless, in order to implement this, a number of practical problems relating to the normalization of the detected angle within the moving average filter (MAF) stage must be resolved to avoid overflow. Additionally, this solution was not designed to operate under variable frequency.

Other kinds of synchronization algorithms are based on the instantaneous symmetrical components theory [18]-[21]. Some of these have a quick dynamic response and can work with variable frequency, but grid harmonics are only attenuated and not completely canceled. However, Yazdani et al. [22] propose an interesting synchronization algorithm consisting of a frequency estimator unit, three adaptive notch filter (ANF) based subfilters and a symmetrical components calculator. It also proposes a modified multiblock structure, which allows harmonic complete cancellation. In [23], a comparison is made between this method, the DSOGI-PLL [24] and the dual second order generalized integrator-frequency locked loop (DSOGI-FLL) [21], which is also based on an ANF, proving that the multiblock three-phase ANF can reduce the time response even if the grid is affected by harmonics.

An alternative method [25] also applies the symmetric components theory and extracts the fundamental frequency positive sequence by performing simple calculations. This completely eliminates several harmonics and employs finite-impulse response filters to attenuate the rest.

Most of these methods are designed to work at a nominal frequency and allow little deviation from this. To overcome 
this drawback, frequency detectors are included in their structures to make them frequency adaptive [26]. A number of other structures have inherently frequency adaptive capability [27]. Nevertheless, these approaches usually increase the complexity, worsen the dynamic response and decrease the capability to work in the presence of distorted voltages.

The use of MAFs in the detection of the positive sequence is relatively recent [17], [28]-[31]. They act as ideal filters when the window width is properly selected for the application. However, in [28], the inclusion of the MAF in the closed loop of the PLL slows down the response and makes the adjustment of the controller more difficult [30]. In [17], the MAF is placed outside the control loop. Thus, the dynamic response of the PLL is faster. Nevertheless, the MAF is applied to the output angle, which may lead to stationary errors in presence of multiple harmonics as detailed in [31]. In [29], the MAF is applied to the $d q$ components of the grid voltages. This solution is optimum, since the dynamics of the PLL is fast and the detection of the angle is very precise. However, it is not frequency adaptive. Its behavior is good under small frequency changes, but leads to a significant phase angle error in the presence of large frequency deviations. However, Freijedo et al. [30] make a correction on the detected angle according to the frequency change. However, since the window width of the MAF is not updated with the frequency, the harmonics are not completely canceled when the frequency changes. Furthermore, the attenuation characteristics of the MAF are slightly degraded.

The synchronization method presented in this paper is based on [29]. Nevertheless, it is extended to make it frequency adaptive. Furthermore, the MAF is analyzed in more detail and more realistic and harder experimental tests are made. This method allows rapid detection of the positive sequence of the grid voltages and is no longer affected by the presence of imbalances or harmonics in the electrical grid.

The paper is organized as follows. Grid voltages are characterized in $d q$ coordinates in Section II. Section III reviews the principles of operation of moving average filters (MAFs). Sections IV and V show the general structure of the proposed filtered-sequence PLL (FSPLL) and a number of simulation results. Section VI is devoted to the frequency detector and variable-frequency FSPLL. Section VII makes a comparative between the proposed detector and other two PLLs found in the literature. The experimental results are described in Section VIII and Section IX sets out the conclusions.

\section{Characterization OF GRID Voltages IN $d q$ COORDINATES}

Grid voltages can be considered a positive sequence with the addition of negative and zero sequences (unbalanced voltages). They can also include harmonic components, which can be either balanced or unbalanced (harmonic distortion). The objective of a positive-sequence detector is to determine the magnitude and phase of the positive-sequence fundamental component, disregarding all unwanted components in the grid voltages.

The grid voltages containing the fundamentals and harmonics, which can be positive or negative sequences, are represented as following:

$$
\begin{aligned}
{\left[\begin{array}{l}
v_{a} \\
v_{b} \\
v_{c}
\end{array}\right]=} & \widehat{V}_{+1}\left[\begin{array}{c}
\cos (\omega t) \\
\cos (\omega t-2 \pi / 3) \\
\cos (\omega t+2 \pi / 3)
\end{array}\right] \\
& +\sum_{\substack{n=-\infty \\
n \neq+1}}^{\infty} \widehat{V}_{n}\left[\begin{array}{c}
\cos \left(n \omega t+\theta_{n}\right) \\
\cos \left(n \omega t-2 \pi / 3+\theta_{n}\right) \\
\cos \left(n \omega t+2 \pi / 3+\theta_{n}\right)
\end{array}\right]
\end{aligned}
$$

in which $\widehat{V}_{+1}$ and $\widehat{V}_{n}$ are the amplitudes of the fundamentals and the harmonics, respectively. Note that for $n=-1$, the second term in (1) corresponds to a fundamental negative sequence.

The voltage vector can be represented in $d q$ coordinates through the Park transformation using a synchronous reference frame rotating at the fundamental frequency. If this transformation is applied to the voltages in (1), the following $v_{d}$ and $v_{q}$ components are obtained

$$
\begin{aligned}
{\left[\begin{array}{l}
v_{d} \\
v_{q}
\end{array}\right]=} & \widehat{V}_{+1} \sqrt{\frac{3}{2}}\left[\begin{array}{c}
\cos \left(\theta_{o}\right) \\
\sin \left(\theta_{o}\right)
\end{array}\right] \\
& +\sum_{\substack{n=-\infty \\
n \neq+1}}^{\infty} \widehat{V}_{n} \sqrt{\frac{3}{2}}\left[\begin{array}{l}
\cos \left[(n-1) \omega t+\theta_{o}+\theta_{n}\right] \\
\sin \left[(n-1) \omega t+\theta_{o}+\theta_{n}\right]
\end{array}\right]
\end{aligned}
$$

where the angle $\theta_{o}$ corresponds to the initial position of the $d$ axis in the $d q$ transformation. It is quite common to synchronize the $d$-axis with the voltage vector $\left(\theta_{o}=0\right)$, hence, under ideal grid voltages, the component in the $q$-axis $\left(v_{q}\right)$ is zero and the component in the $d$-axis $\left(v_{d}\right)$ is constant and takes the maximum value $\widehat{V}_{+1} \sqrt{3 / 2}$.

However, according to (2), voltage imbalances and distortion will cause oscillations in the two components $\left(v_{d}\right.$ and $\left.v_{q}\right)$. The frequency of these oscillations is $(n-1) \omega$ for a positive-sequence harmonic and $(|n|+1) \omega$ for a negative sequence. Therefore, one can conclude that a negative sequence and odd-order harmonics generate even-order frequency oscillations, and even-order harmonics generate odd-order frequency oscillations.

\section{MAF}

In order to use $v_{d}$ and $v_{q}$ components to obtain the real angle of the positive sequence, the oscillations caused by distortion have to be removed. An MAF structure may be very useful because, under certain conditions, it can perform as an ideal low-pass filter. The performance of the MAF is analyzed in the following.

Application of the MAF operator to an input signal $x(\tau)$ is given by

$$
\bar{x}(t)=\frac{1}{T_{w}} \int_{t-T_{w}}^{t} x(\tau) d \tau .
$$

An example of the performance of the MAF is shown in Fig. 1. The filter provides the mean value of the input signal in the time period from $t-T_{w}$ to $t$, where $T_{w}$ is the window width. There is always an intrinsic delay related to the window width; therefore, 


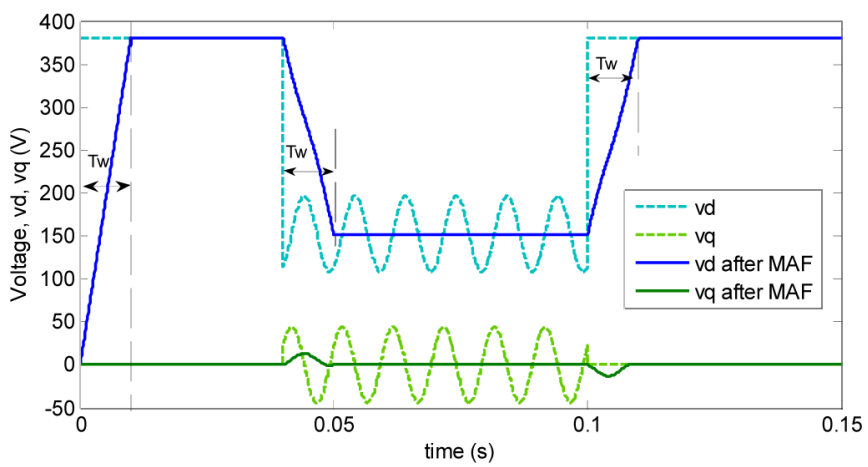

Fig. 1. Performance example of the MAF.

the larger $T_{w}$ is, the slower the detection dynamic. If the input signal contains sinusoidal components, whose frequency is an integer multiple of the equivalent frequency of the $\operatorname{MAF}\left(f_{w}=\right.$ $\left.1 / T_{w}\right)$, the output signal will be free of oscillations containing only the mean value of the input signal. The MAF will need a period of time $T_{w}$ to gather the data and obtain the correct output, hence, this is the delay produced by the MAF.

In Fig. 1, grid voltages suffer an asymmetric voltage dip $(20 \%, 40 \%$, and $60 \%)$ that generates a negative sequence in the $d q$ components. The window width is $0.01 \mathrm{~s}$, that is half the input signal period and exactly the negative-sequence period. The MAF can eliminate the input oscillation after gathering the data. When the input signal changes suddenly, the output of the MAF has an error during $T_{w}$ until the window contains an integer number of oscillations and the MAF obtains again the mean value.

Selection of the window width is an important issue. Depending on this, the MAF is able to perform as an ideal low-pass filter for some input frequency components.

For a better understanding of the MAF, the transfer function has been obtained and analyzed. Given an input signal

$$
x(t)=A \sin \left(\omega t+\theta_{0}\right)
$$

with $\omega=2 \pi / T$. The output of the MAF will be

$$
\bar{x}(t)=\frac{A}{\omega T_{w}}\left\{\cos \left[\omega\left(t-T_{w}\right)+\theta_{0}\right]-\cos \left(\omega t+\theta_{0}\right)\right\} .
$$

Applying the Laplace transform to (4) and (5), the transfer function for $\theta_{0}=0$ becomes

$$
G_{\mathrm{MAF}}(s)=\frac{\bar{X}(s)}{X(s)}=\frac{\omega \sin \left(\omega T_{w}\right)-s\left[1-\cos \left(\omega T_{w}\right)\right]}{\omega^{2} T_{w}} .
$$

Substituting $s=j \omega$

$$
G_{\mathrm{MAF}}(j \omega)=\frac{\bar{X}(j \omega)}{X(j \omega)}=\frac{\sin \left(\omega T_{w}\right)-j\left[1-\cos \left(\omega T_{w}\right)\right]}{\omega T_{w}} .
$$

The magnitude and phase expressions are as following:

$$
\left|G_{\mathrm{MAF}}(j \omega)\right|=\frac{\sqrt{2}}{\omega T_{w}} \sqrt{1-\cos \left(\omega T_{w}\right)}
$$

and

$$
\varphi\left[G_{\mathrm{MAF}}(j \omega)\right]=-\arctan \left[\frac{1-\cos \left(\omega T_{w}\right)}{\sin \left(\omega T_{w}\right)}\right]=-\frac{\omega T_{w}}{2} .
$$
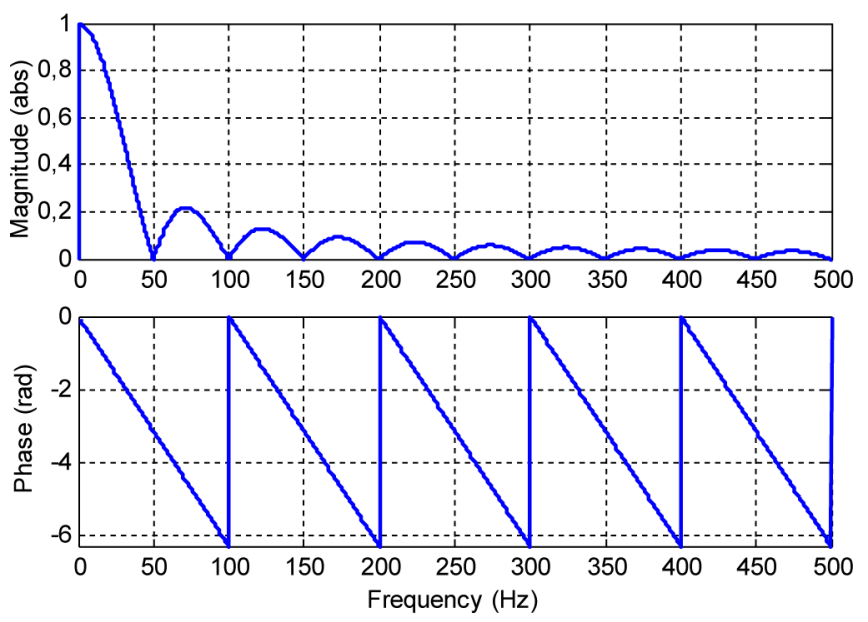

Fig. 2. Frequency response of the MAF.

The MAF is a finite-impulse response (FIR) filter that, as shown in (9), has linear-phase response, being the time of the delay constant and known.

From (8), the output magnitude of the MAF is zero whenever $\left[1-\cos \left(\omega T_{w}\right)\right]=0$, i.e.,

$$
\omega T_{w}=k 2 \pi \quad \text { for } k=1,2,3, \ldots
$$

or

$$
\frac{T_{w}}{T}=\frac{f}{f_{w}}=k \quad \text { for } k=1,2,3, \ldots
$$

Fig. 2 shows the frequency response of the MAF. In this representation, the window width of the MAF is $T_{\omega}=T$, being $T$ the input signal period. Observe that the frequency components that comply with (11) are canceled completely; therefore, all of the input signal are harmonics. The frequency components close to the filter-node frequencies will not be canceled, but very attenuated. Additionally, according to (9), the MAF shows linear phase.

When using the MAF to filter $d q$ components, if $T_{w}=T / 2$, the $d q$ even-order oscillations from odd-order harmonics and the negative sequence would be completely removed. If evenorder harmonics with significant amplitudes are expected, the window width of the MAF should be increased to $T_{w}=T$.

\section{FSPLL}

Fig. 3 shows the structure of the proposed positive-sequence detector. First, the grid voltage vector is transformed using a synchronous reference frame rotating at fundamental frequency $\left(\omega_{f}\right)$ and with an arbitrary angular position $\left(\theta_{f}\right)$. The components $v_{d}$ and $v_{q}$ may contain oscillations due to harmonics and a negative voltage sequence. Both components are thus filtered through the MAF; therefore, if an appropriate window width is used, $\bar{v}_{d}$ and $\bar{v}_{q}$ will be constant and containing only the positive sequence of the grid voltages.

As shown in Fig. 4, the $\bar{v}_{q}$ component is not necessarily zero because the angle used in the Park transformation is arbitrary. Thus, the voltage vector is not on the $d$-axis, but on another 


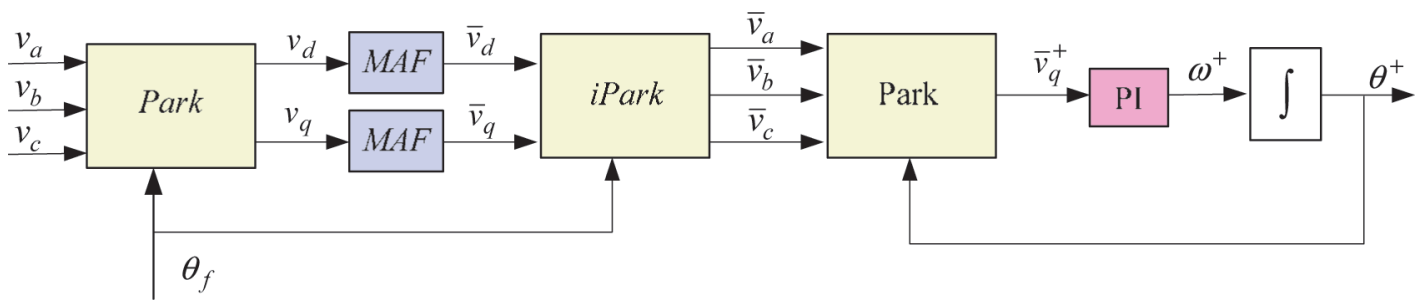

Fig. 3. Structure of the proposed PLL.

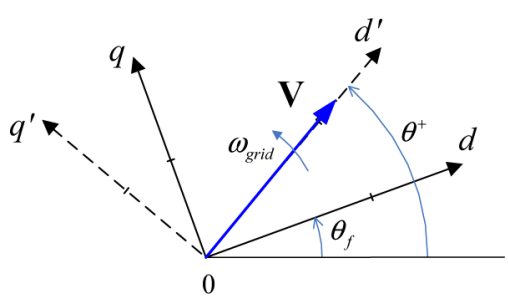

Fig. 4. Synchronization diagram of the proposed PLL.

$d^{\prime}$-axis of a reference frame rotating at $\omega_{\text {grid }}$ with an unknown angular position $\theta^{+}$.

In this structure, the $d q$ output variables of the MAF are transformed back into $a b c$ components with the same arbitrary angle $\theta_{f}$. The obtained signals $\left(\bar{v}_{a}, \bar{v}_{b}, \bar{v}_{c}\right)$ correspond to the fundamental positive-sequence grid voltages, and therefore, they are clean of any distortion or imbalance. For this reason, this stage is considered to perform as a quasi-ideal filter for the three-phase voltage components. The variables are again transformed into $d q$ coordinates, but in this case, the synchronization angle $\left(\theta^{+}\right)$ is obtained by a classical control loop that forces the component $\bar{v}_{q}^{+}$to be zero through a proportional and integral (PI) regulator. The output of the PI $\left(\omega^{+}\right)$is integrated to obtain $\theta^{+}$. It should be remarked that, in this structure, the PI regulator parameters can be tuned to achieve a quick response of the PLL because unwanted oscillations are not expected in the $\bar{v}_{q}^{+}$component. This is a significant advantage compared with other methods [14], which do not include the filtering stage presented in this paper.

The same structure of Fig. 3 can be used to obtain the negative sequence of the input grid voltages by imposing on the Park and iPark transformations an arbitrary angle rotating in the opposite direction $\left(\theta^{-}=-\theta^{+}\right)$.

\section{Simulation Results}

The FSPLL has been simulated in order to test its performance. Simulation results have been obtained through MATLAB/Simulink. In both simulations, the rms line-to-neutral grid voltage is $220 \mathrm{~V}$ at $50 \mathrm{~Hz}$, and both Park and iPark transformations are tuned to perform at $50 \mathrm{~Hz}$. A window width of $T_{w}=T / 2$, where $T$ is the grid voltage period, is selected for the MAFs. The main variables of the proposed FSPLL are displayed: (a) grid voltages; (b) the $d q$ components before and (c) after the MAF; (d) the $d q$ synchronized variables in the PLL; (e) the input voltage positive sequence; (f) the real (red) and detected angle (blue); and (g) the error in the detected angle.
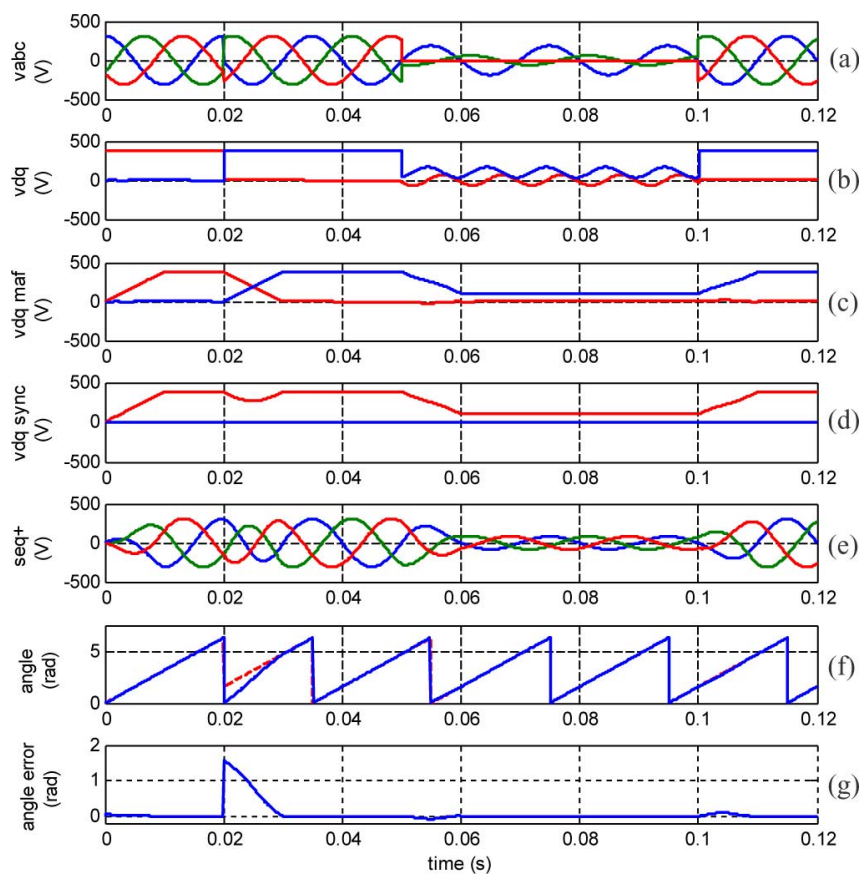

Fig. 5. FSPLL simulation results phase jump and voltage dip. (a) Grid voltages. (b) $d q$ components before and (c) after the MAF. (d) $d q$ synchronized variables in the PLL. (e) Positive sequence of the input grid voltages. (f) Real (dashed) and detected angle. (g) Error in the detected angle.

The MAF needs a $T_{w}$ time to collect all the data $(10 \mathrm{~ms})$. After that, the FSPLL detects the angle without error.

In Fig. 5, a $\pi / 2$ phase jump is introduced at $t=20 \mathrm{~ms}$. The detected angle has an initial error of $\pi / 2$ that is corrected in a $T_{w}$ time. At $t=50 \mathrm{~ms}$, an asymmetrical voltage dip is introduced $(60 \%, 20 \%$, and $0 \%)$, thus, a fundamental negative sequence appears in the $d q$ components. The oscilations are canceled completely after the MAF in a $T_{w}$ time.

Fig. 6 shows another simulation test performed in the FSPLL structure. At $t=30 \mathrm{~ms}$, an asymmetrical voltage dip is introduced $(60 \%, 40 \%$, and $20 \%)$. At $t=60 \mathrm{~ms}$, an odd harmonic component set is added as follows: third (30\%), fifth (40\%), and seventh (20\%). Observe that the FSPLL has a very good performance, rapidly eliminating the error in the detected angle within half a grid period $(10 \mathrm{~ms})$ when any disturbance appears.

Note that again, the $d q$ components before the MAF contain oscillations, which are canceled completely after the MAF. These oscillations are produced first, because a fundamental negative sequence appears due to the voltage dip process, and 

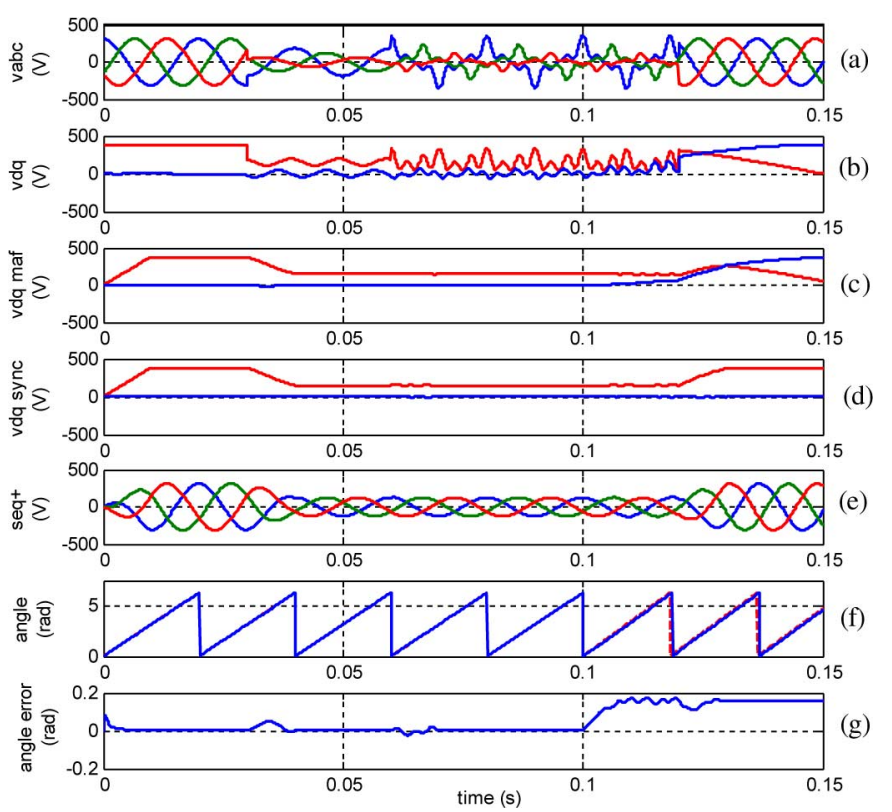

Fig. 6. Constant-frequency FSPLL simulation results. Voltage dip, harmonics, and frequency change. (a) Grid voltages. (b) $d q$ components before and (c) after the MAF. (d) $d q$ synchronized variables in the PLL. (e) Positive sequence of the input grid voltages. (f) Real (dashed) and detected angle. (g) Error in the detected angle.

next, due to the harmonic distortion. From the results, one can conclude that the proposed FSPLL can overcome phase jumps, voltage dips, and high harmonic distortion.

At $t=100 \mathrm{~ms}$, the grid frequency changes up to $55 \mathrm{~Hz}$. Now the detected angle shows a constant error of 0.16 rad approximately, even when the disturbances in the grid voltages disappear. This is due to the fact that first, Park and iPark transformations use a synchronous frame rotating at a frequency different from the fundamental of the grid $\left(\omega_{f}\right)$, and second, the window width of the MAF is set to a different frequency, thus, it will not contain an integer number of oscillations of the $d q$ components and will not be able to filter them properly. As shown in Fig. 2, if the frequency is not exact, oscillations will not be canceled, but attenuated.

As shown in this example, the proposed positive-sequence detector has a very good performance in the presence of grid disturbances. However, a grid frequency other than the nominal value will produce a proportional error in the detected angle.

\section{VARIABLE-FREQUENCY FSPLL}

\section{A. Frequency Detector}

To make the FSPLL frequency adaptive, the real frequency should be measured to update the frequency dependent blocks. Several methods for the frequency measurement have been proposed in the literature. There are the methods based on zerocrossing detection [32]-[39], Fourier transform [36], [40], [41], Kalman filtering [42], PLL based [43], and adaptive notch filter based [44].

Among these, the ones based on zero-crossing detection are the simplest. The main idea of these methods is to measure the time elapsed between two consecutive zero crossings of the grid voltage, and as a function of this time, estimate the frequency. These methods work quite well under undistorted grid conditions. However, in the presence of harmonics or other grid disturbances, they may lead to erroneous frequency estimations due to the nonreal crossing points caused by the distortion. In order to improve its behavior under these circumstances, several algorithms have been proposed [32]-[39]. Almost all of them are based on the attenuation of the undesired harmonic components and noise as a prior stage. For example, Asnin et al. [32] and [33] propose a prior filter stage based on a FIR filter. A more complicated multistage filter is introduced in [34] and [35]. In both cases, the aim of including the filters is to attenuate the grid voltage distortion.

In [36], the required filter stage is implemented making use of a discrete Fourier transformation (DFT) working with a fixed window width. In this case, if the width of the window is equal to the period of the grid voltage, the DFT algorithm works as an ideal low-pass filter. On the other hand, if the width of the window does not match exactly the period of the voltage, the DFT does not work as an ideal low-pass filter, but its behavior is still good enough to estimate the frequency. Finally, in a number of literatures [37]-[39], the grid voltages are approximated by a low-order polynomial coefficients of which are obtained making use of the least-square technique (LST). In these cases, due to the low order of the chosen polynomial, the high-frequency components of the grid voltages are attenuated.

The positive-sequence detector proposed in this paper does not need a very accurate frequency measurement to operate properly. A slight frequency change affects mainly two blocks: Park and iPark transformations, and the MAFs. If the angle of the Park transformation has not exactly the same frequency as the grid voltage, the transformed $v_{d}$ and $v_{q}$ will not be constant. They will oscillate at a frequency of the difference between the real frequency and the transformation frequency. In the case of the MAFs, the window width will not match exactly the period of the input signal oscillation. Consequently, imbalances and harmonic disturbances will not be canceled by the MAFs completely, however, they will be very attenuated, as shown in Fig. 2. This error is analyzed in the following. A slight frequency difference is represented as follows:

$$
\omega_{d}=\omega_{\text {real }}-\omega_{f}
$$

where $\omega_{\text {real }}$ is the real-grid frequency and $\omega_{f}$ is the frequency fixed for the Park and iPark transformations and the MAFs. The main frequency of the transformed $d q$ components will be $\omega_{d}$. From (7)

$$
\lim _{\omega \rightarrow 0} G_{\mathrm{MAF}}(j \omega)=1
$$

what for $\omega=0$ implies

$$
\begin{aligned}
\left|G_{\mathrm{MAF}}(j \omega)\right| & =1 \quad \text { and } \\
\varphi\left[G_{\mathrm{MAF}}(j \omega)\right] & =0 .
\end{aligned}
$$

For a relatively small frequency as $\omega_{d},(8)$ and (9), and Fig. 2, show that the error in magnitude and phase will be very small. For example, for $\omega_{d}=0.5 \mathrm{~Hz}$ being $T_{w}=0.01 \mathrm{~s}$ (half the input 


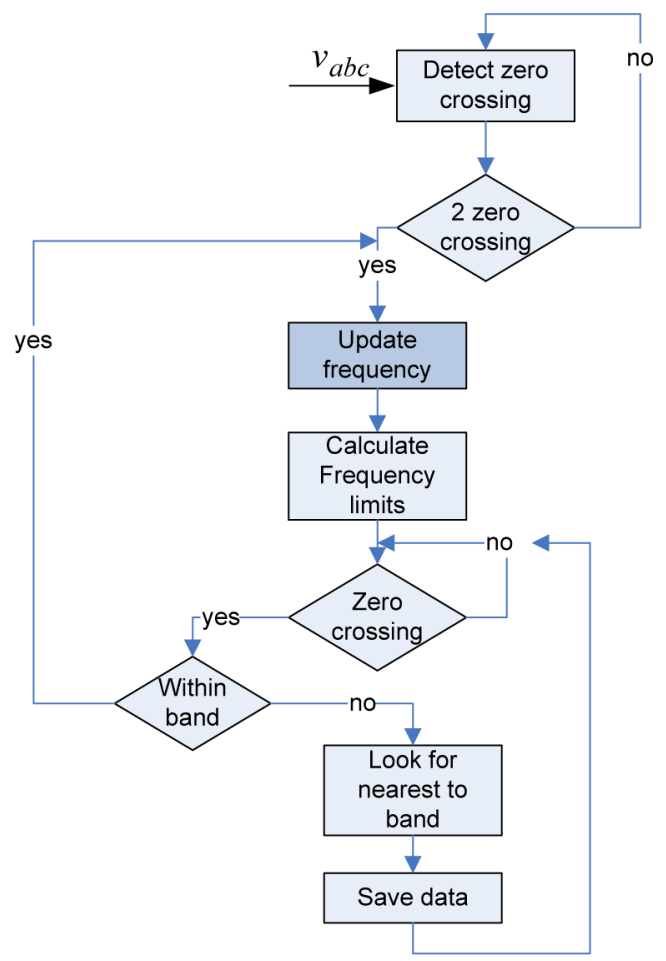

Fig. 7. Block diagram of the frequency detector.

signal period), the magnitude and phase result in

$$
\begin{aligned}
\left|G_{\mathrm{MAF}}(j \omega)\right| & =0.9993 \quad \text { and } \\
\varphi\left[G_{\mathrm{MAF}}(j \omega)\right] & =0.0157
\end{aligned}
$$

what proves a very small error in the filtered components, and thus, in the detected angle.

Therefore, in this paper, a relatively simple, but efficient adaptive zero-crossing method is proposed. Fig. 7 shows the flowchart of this detection method. At the beginning of the process, two zero-crossing points are needed to calculate the initial frequency. The detector has been designed to allow frequency changes of up to $25 \mathrm{~Hz} / \mathrm{s}$. Hence, every time the frequency is updated, the upper and lower frequency limits are calculated to determine a $25-\mathrm{Hz} / \mathrm{s}$ frequency band around this new frequency. Then, it will wait for the following zero-crossing point and proceed differently depending on weather it is within the band or not. If it is within the band, the frequency is updated and the new limits are calculated. If not, it will look before and after the band, which is the closest zero-crossing point to the band, and save it. Neither the frequency nor the frequency limits will be updated with this last point, but the detector will start counting from it waiting for the next zero-crossing point. Both the positive- and negative-slope zero-crossing points can be used for detecting the frequency in order to improve the detection dynamics. The best way to avoid errors due to transitories when disturbances appear, is to use both crossing points and calculate the frequency separately.

The following situations may occur depending on the location of the next zero-crossing point.

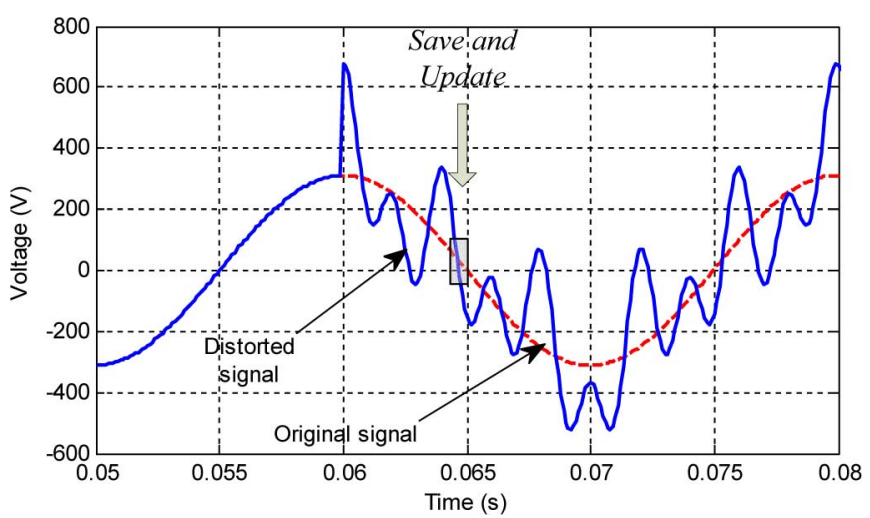

Fig. 8. Zero crossing in the accepted band.

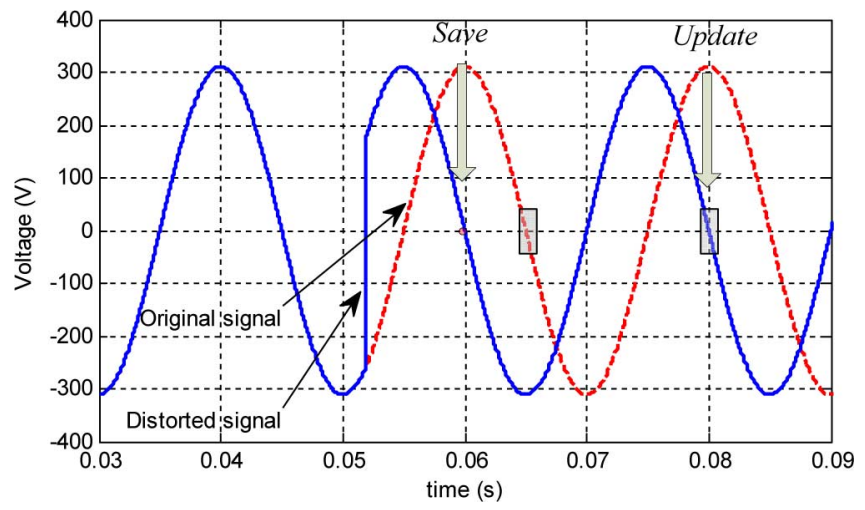

Fig. 9. Zero crossing outside the accepted band.

1) A zero-crossing point is found in the $25 \mathrm{~Hz} / \mathrm{s}$ band. It is considered to be a valid value and the frequency is updated. This situation is shown in Fig. 8. Grid voltages start undisturbed and suddenly one harmonic component is added. In this case, the transition is not strong enough and the zero-crossing point is found within the band. Any other zero-crossing point before or after the band may not be considered if there has been a crossing point within the band.

2) There are several zero-crossing points within the band. When the first zero-crossing point is found, the frequency is updated and the new band limits are calculated. The algorithm will look for a new zero-crossing point much further from the second zero-crossing point. Hence, this will be outside the new band, and therefore, will not be considered.

3) There is a zero-crossing point before the band. This is shown in Fig. 9. This zero-crossing point would represent an important frequency change and may not be real, but caused by a transitory disturbance, in this case, the sudden addition of a harmonic component set. This uncertain crossing point is saved, but the frequency is not updated. If the next zero-crossing point is found in the $25 \mathrm{~Hz} / \mathrm{s}$ band of the previous one, the frequency will then be updated.

4) There is a zero-crossing point after the band. If no zerocrossing point is found before or within the band, this uncertain crossing point is saved, but the frequency is not 

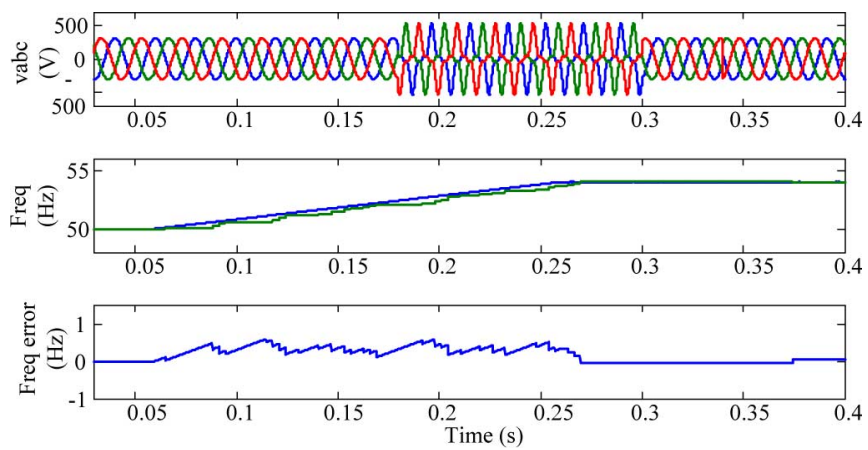

Fig. 10. Simulation result of the proposed frequency detector. (a) Grid voltages. (b) Detected frequency. (c) Detected frequency error.

updated. If the next zero-crossing point is found in the $25 \mathrm{~Hz} / \mathrm{s}$ band of the previous one, the frequency will then be updated.

5) There are zero-crossing points before and after the band. In this case, the nearest point to the band is taken and saved, but again, the frequency is not updated until the next zerocrossing point is within the band. This could represent nonreal-crossing points due to any kind of disturbance and the frequency will be updated properly within a grid voltage cycle.

When no zero-crossing point is found in the band, the nearest point to the band is saved. This is usually due to a transitory in the grid voltage. The waveform will be periodical, and thus, in the following period a new zero-crossing point will be found within the band of the saved one and the frequency updated.

There are several ways of performing the method. In this PLL application, a high level of precision is not required because deviations of up to $1 \mathrm{~Hz}$ provoke a slight, but acceptable level of error in the positive-sequence detection. However, it is preferable to apply the method to more than one phase. It can be applied to line-to-neutral phases, line-to-line phases, or $\alpha-\beta$ transformed phases.

1) Line-to-neutral voltages: Three frequency detectors are needed. The average of the detected three frequencies is accepted as the frequency value. Any frequency change will be detected quickly, up to three measurements are made within a period. When a phase fails, the average of the remaining phases will be used. If two phases fail, the frequency will be calculated with the remaining phase.

2) Line-to-line voltages: This is similar to the previous case. The only difference is that if one phase fails, there will still be three line-to-line phases to detect the frequency. Only when two phases fail one line-to-line phase will go to zero.

3) $\alpha-\beta$ transformed components: This only needs two frequency detectors, but the frequency is updated less often. $\alpha-\beta$ components can still be used when a phase fails. Furthermore, if two phases fail, one variable ( $\alpha$ or $\beta$ ) can still be used for the frequency update.

Fig. 10 shows the performance of the frequency detector in the presence of distorted grid voltages when the frequency varies. The simulation starts with $220 \mathrm{~V}$ at $50 \mathrm{~Hz}$. At $t=60 \mathrm{~ms}$, the
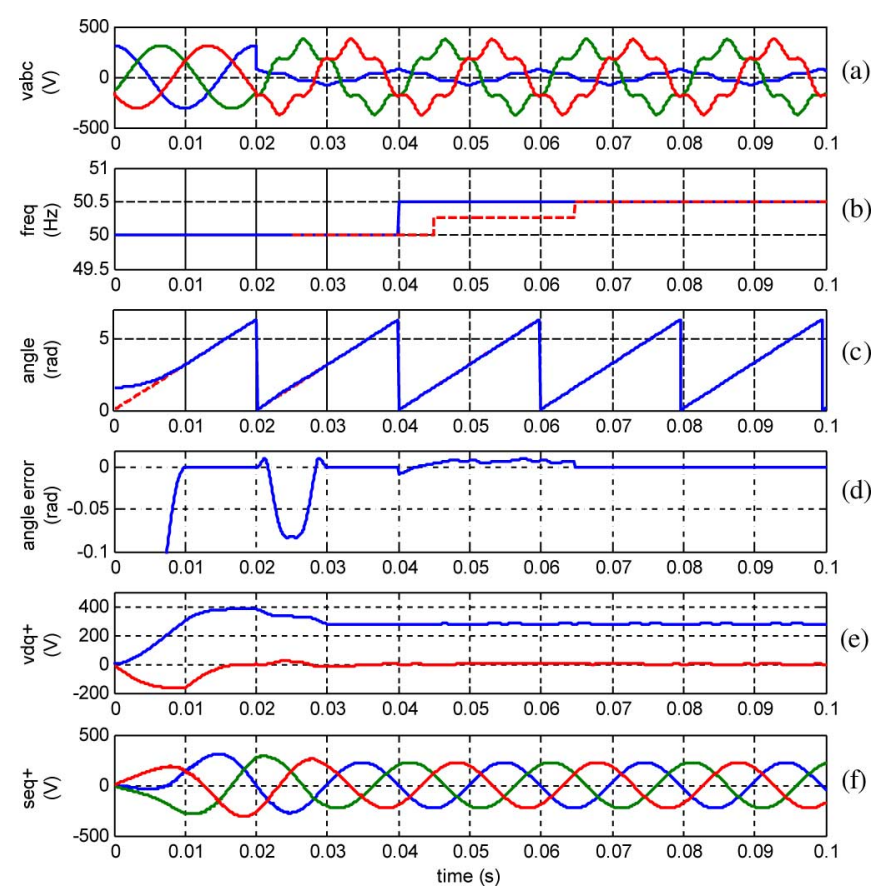

Fig. 11. Variable-frequency FSPLL simulation results. $0.5 \mathrm{~Hz}$ step-frequency change with a distorted grid. (a) Grid voltages. (b) Real and detected (dashed) frequency. (c) Real (dashed) and detected angle. (d) Error in the detected angle. (e) $d q$ components of the positive sequence. (f) Positive sequence of the input grid voltages.
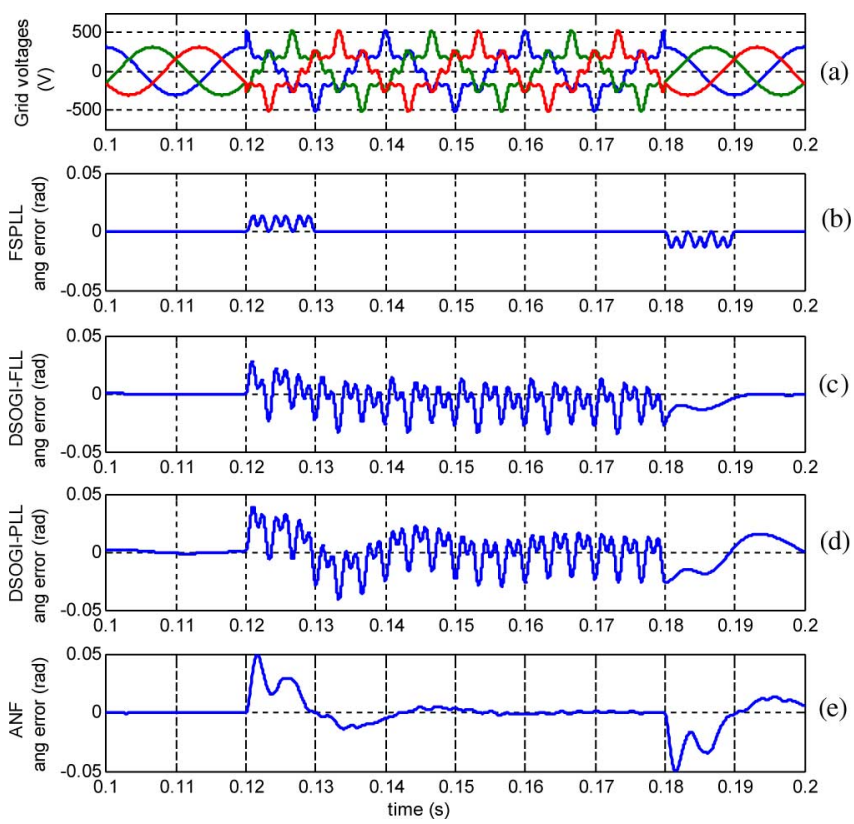

Fig. 12. Comparative simulation in the presence of harmonics. (a) Grid voltages. (b) Error in the detected angle for the FSPLL. (c) Error in the detected angle for DSOGI-FLL. (d) Error in the detected angle for DSOGI-PLL.

frequency starts increasing at $20 \mathrm{~Hz} / \mathrm{s}$ and it reaches $54 \mathrm{~Hz}$ at the end of the simulation. At $t=180 \mathrm{~ms}$ third and fifth harmonics are included with an amplitude of 50\% and 30\% of the fundamental. Observe that the error in the frequency detected is small during the variation until it stabilizes. The FSPLL hardly notices this error. At $t=340 \mathrm{~ms}$, a phase jump of $\pi$ is introduced. A 


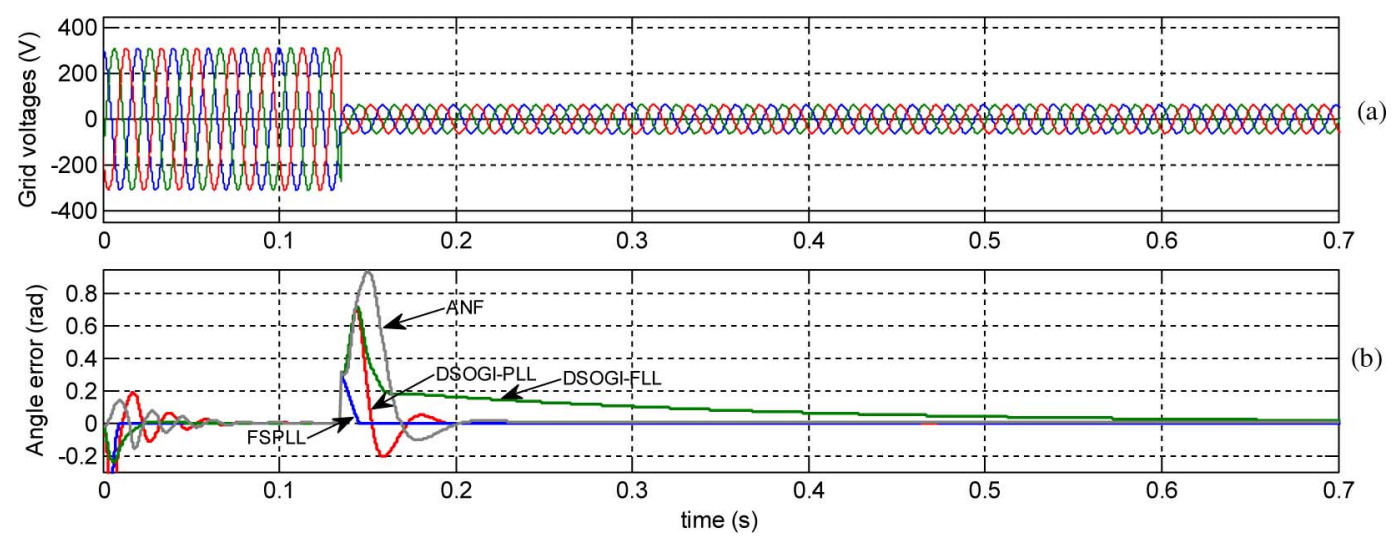

Fig. 13. Comparative simulation in the presence of a voltage dip and phase jump. (a) Grid voltages. (b) Error in the detected angle for the FSPLL, DSOGI-FLL, and DSOGI-PLL.

TABLE I

COMPARATIVE IN THE PRESENCE OF HARMONICS

\begin{tabular}{c|c|c|c|c} 
& FSPLL & DSOGI-FLL & DSOGI-PLL & 3ph-ANF \\
\hline$e_{\text {phase }}(\mathrm{rad})$ & 0 & 0.023 & 0.015 & 0 \\
\hline$t_{0 \text { phase }}(\mathrm{s})$ & $T_{w}$ & - & - & 0.05 \\
\hline$e_{\text {mag }}(\mathrm{V})$ & 0 & 27.5 & 25 & 0 \\
\hline$t_{0 \text { mag }}(\mathrm{s})$ & $T_{w}$ & - & - & 0.05 \\
\hline$e_{\text {freq }}(\mathrm{Hz})$ & \pm 1 sample & 1.6 & 1.8 & 0 \\
\hline$t_{0 \text { freq }}(\mathrm{s})$ & - & - & - & 0.05 \\
\hline
\end{tabular}

phase jump is usually the worst disturbance for a frequency detector. Note that the proposed frequency detector is not affected by such an abrupt phase jump.

\section{B. Variable-Frequency FSPLL}

In the structure shown in Fig. 3, several blocks are designed to perform at a constant frequency. The simulation test shown in Fig. 6 proves that a grid frequency different from the one selected will provoke errors in the FSPLL variables. To solve this problem, the frequency-dependent blocks have to be updated with the calculated frequency. One of the parameters that needs to be changed is the frequency of the arbitrary angle used in the Park and iPark transformations. In this way, the transformed $d q$ components will be constant without the low-frequency oscillation produced by the frequency difference. Also the MAF window width has to be updated in accordance with the estimated frequency. Consequently, the MAF window will always contain an integer number of unwanted oscillations, thus being capable of filtering them.

Fig. 11 shows a simulation of the variable-frequency FSPLL for a frequency step change of $0.5 \mathrm{~Hz}$ in the presence of a singlephase voltage dip (20\%) and a fifth-order harmonic (20\%). The frequency detector takes approximately one cycle to detect the correct frequency, meanwhile the FSPLL has a little and acceptable error. This error is too little to be noticed in the detected positive sequence.

\section{COMPARATIVE Simulations}

The proposed variable-frequency FSPLL has been compared in the presence of the main grid disturbances, to other three representative detectors found in the literature: the DSOGIPLL [24], the DSOGI-FLL [21], and the three-phase ANF [22].
TABLE II

Comparative in the Presence of a Voltage Dip

\begin{tabular}{c|c|c|c|c} 
& FSPLL & DSOGI-FLL & DSOGI-PLL & 3ph-ANF \\
\hline$e_{\text {phase }}(\mathrm{rad})$ & 0 & 0 & 0 & 0 \\
\hline$t s_{\text {phase }}(\mathrm{s})$ & $T_{w}(0 \%)$ & 0.145 & 0.033 & 0.048 \\
\hline$e_{\text {mag }}(\mathrm{V})$ & 0 & 0 & 0 & 0 \\
\hline$t s_{\text {mag }}(\mathrm{s})$ & $T_{w}(0 \%)$ & 0.42 & 0.022 & 0.045 \\
\hline$e_{\text {freq }}(\mathrm{Hz})$ & \pm 1 sample & 0 & 0 & 0 \\
\hline$t s_{\text {freq }}(\mathrm{s})$ & - & 0.455 & 0.049 & 0.053 \\
\hline
\end{tabular}

TABLE III

Comparative in the Presence of A Phase Jump

\begin{tabular}{c|c|c|c|c} 
& FSPLL & DSOGI-FLL & DSOGI-PLL & 3ph-ANF \\
\hline$e_{\text {phase }}(\mathrm{rad})$ & 0 & 0 & 0 & 0 \\
\hline$t s_{\text {phase }}(\mathrm{s})$ & $T_{w}(0 \%)$ & 0.1185 & 0.1432 & 0.028 \\
\hline$e_{\text {mag }}(\mathrm{V})$ & 0 & 0 & 0 & 0 \\
\hline$t s_{\text {mag }}(\mathrm{s})$ & $T_{w}(0 \%)$ & 0.114 & 0.1565 & 0.05 \\
\hline$e_{\text {freq }}(\mathrm{Hz})$ & \pm 1 sample & 0 & 0 & 0 \\
\hline$t s_{\text {freq }}(\mathrm{s})$ & - & 0.12 & 0.1795 & 0.07 \\
\hline
\end{tabular}

TABLE IV

Comparative In the PresenCE OF A STEP-FreQuenCy VARIATION

\begin{tabular}{c|c|c|c|c} 
& FSPLL & DSOGI-FLL & DSOGI-PLL & 3ph-ANF \\
\hline$e_{\text {phase }}(\mathrm{rad})$ & 0 & 0 & 0 & 0 \\
\hline$t_{0 \text { phase }}(\mathrm{s})$ & 0.025 & 0.05 & 0.15 & 0.1 \\
\hline$e_{\text {mag }}(\mathrm{V})$ & 0 & 0 & 0 & 0 \\
\hline$t_{0 \text { mag }}(\mathrm{s})$ & 0.025 & 0.05 & 0.15 & 0.1 \\
\hline$e_{\text {freq }}(\mathrm{Hz})$ & \pm 1 sample & 0 & 0 & 0 \\
\hline$t_{0 \text { freq }}(\mathrm{s})$ & 0.025 & 0.05 & 0.12 & 0.1
\end{tabular}

The detectors have been modeled and tuned as described in the references.

In the next simulations, the rms line-to-neutral grid voltage is $220 \mathrm{~V}$ at $50 \mathrm{~Hz}$. In Fig. 12, an odd harmonic component set is added as follows: fifth (30\%), seventh (20\%), and 11th (30\%). In the presence of harmonics, the FSPLL needs a $T_{w}$ time to correct the error, while the DSOGI-FLL and the DSOGI-PLL cannot completely cancel the effects of the harmonics and maintain an error. The three-phase ANF can also remove completely the error.

Fig. 13 shows the behavior of the three PLLs in the presence of a three-phase voltage dip (20\%) and a $\pi / 10$ phase jump. Again, the FSPLL needs a $T_{w}$ time to completely correct the error. The DSOGI-PLL and the three-phase ANF have a higher transitory error, but a fast performance, while the DSOGI-FLL has slower dynamics.

Tables I-IV summarize the performance of the four detectors in the presence of the main grid disturbances. The following 


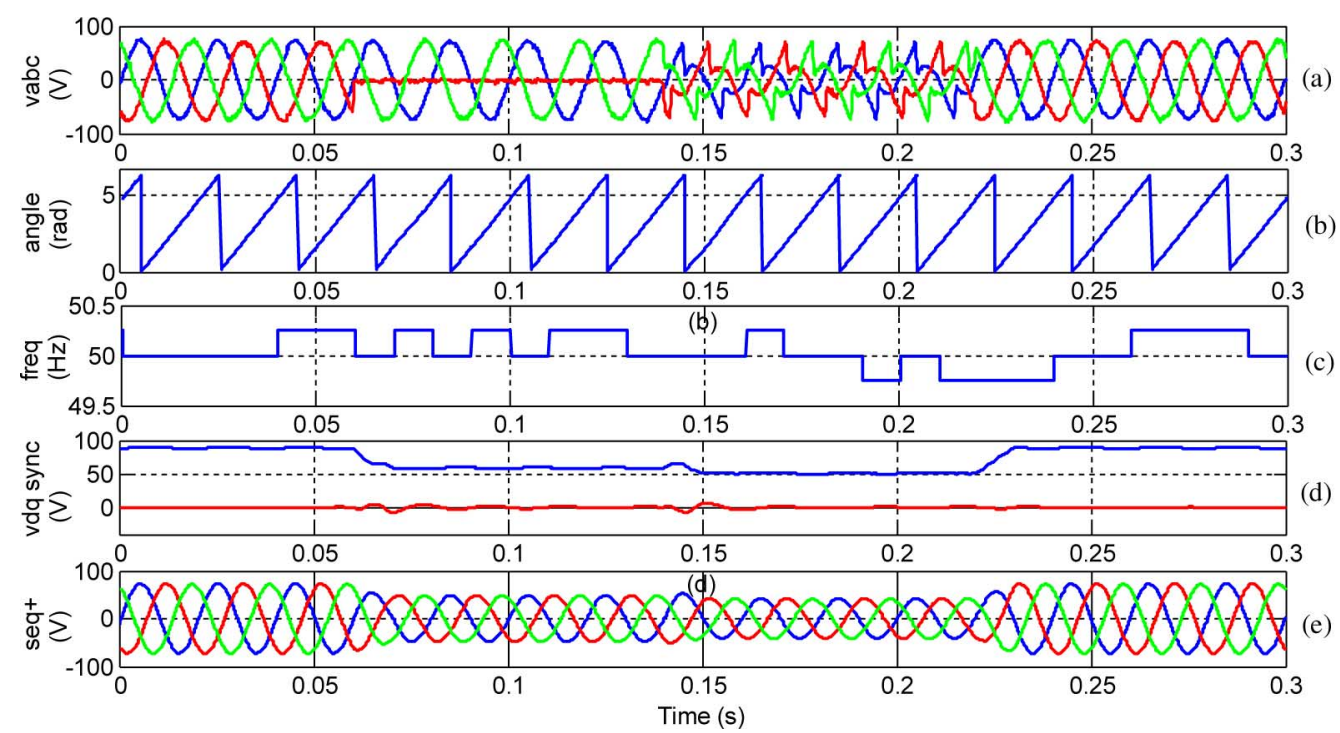

Fig. 14. Experimental results. Constant-frequency input, voltage dip, and high harmonic distortion. (a) Grid voltages. (b) Detected angle. (c) Detected frequency. (d) $d q$ synchronized variables in the PLL. (e) Positive sequence.

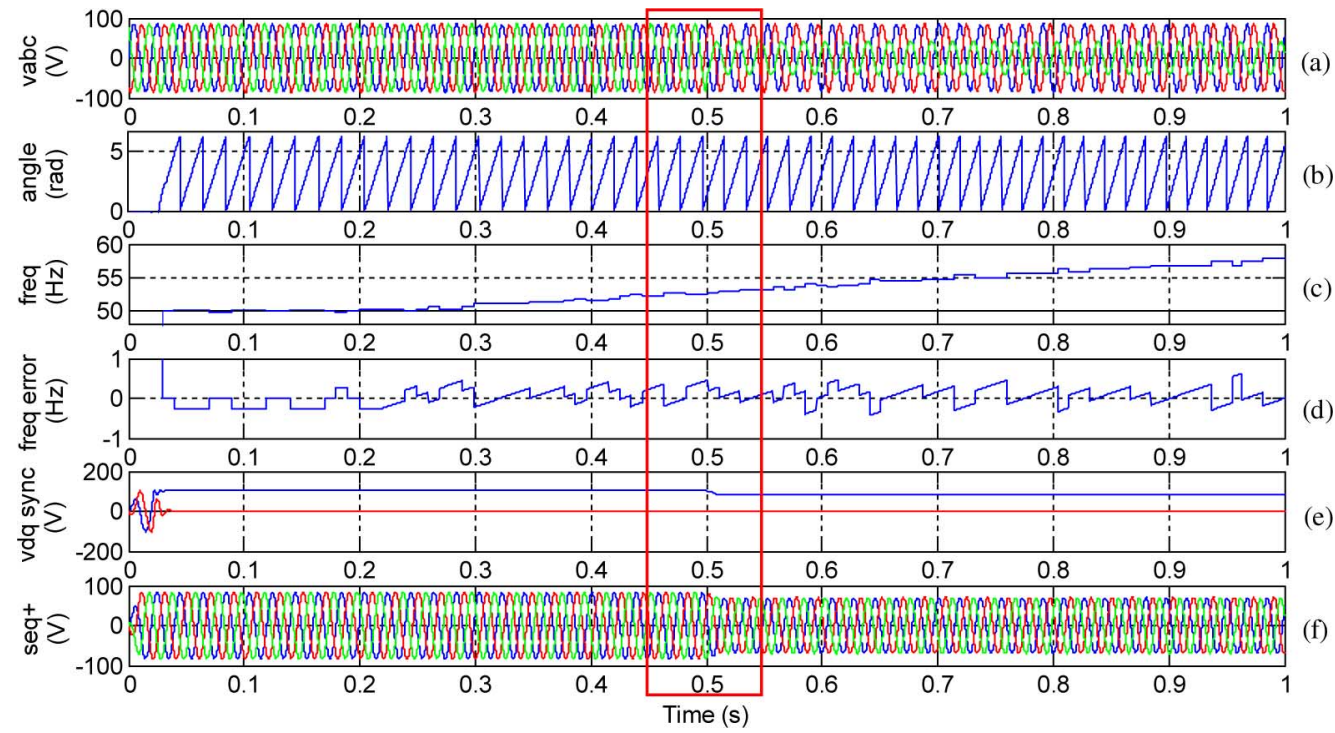

Fig. 15. Experimental results. Varying-frequency input and voltage dip. (a) Grid voltages. (b) Detected angle. (c) Detected frequency. (d) Error in the detected frequency. (e) $d q$ synchronized variables in the PLL. (f) Positive sequence.

data are displayed. The stationary errors in the detected phase $\left(e_{\text {phase }}\right)$, the detected magnitude of the positive sequence $\left(e_{\mathrm{mag}}\right)$, and the detected frequency $\left(e_{\text {freq }}\right)$. Additionally, the settling time of the detected phase ( $\left.t s_{\text {phase }}\right)$, detected magnitude of the positive sequence $\left(t s_{\mathrm{mag}}\right)$, and detected frequency $\left(t s_{\text {freq }}\right)$ within the $2 \%$ of the steady state for the DSOGI-FLL, DSOGI-PLL, and three-phase ANF are shown. In the case of the variablefrequency FSPLL, this time corresponds to the time needed to correct the error completely ( $0 \%$ of the steady state). These data have been obtained through simulation. In this study, the instants of transitions and the harmonic phases are on the basis of the worst case for all the sequence detectors under evaluation.

Table I shows a comparative when an odd-order harmonic component set fifth (30\%) and seventh (20\%) is added. As shown in Fig. 12, the variable-frequency FSPLL and the three-phase
ANF cancel the effects of the harmonics, while the other two PLLs can only attenuate the error.

In Tables II and III, the behavior of the four detectors when a three-phase voltage dip (20\%) appears and the effect of a phase jump of $2 \pi / 3$ is analyzed separately. In both cases, all the detectors achieve zero stationary errors. Again, the variable-frequency FSPLL needs a $T_{w}$ time to completely remove the errors. The settling time $(2 \%)$ is shown for the other three detectors.

Finally, in Table IV, the effect of a frequency step change of $0.5 \mathrm{~Hz}$ is shown. In this case, all the detectors achieve zero stationary errors, and $t_{0 \text { phase }}, t_{0 \mathrm{mag}}$, and $t_{0 \text { freq }}$ represent the time needed to achieve the steady state (within $0 \%$ of error).

As shown in this comparison, the main advantages of the proposed variable-frequency FSPLL are the complete cancellation 


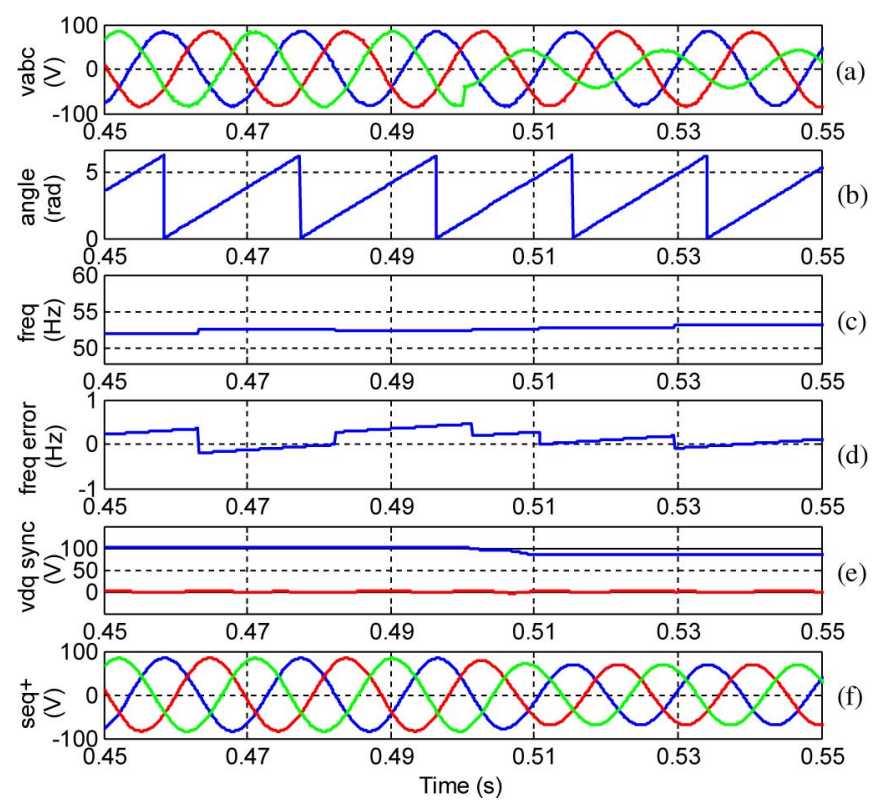

Fig. 16. Experimental results. Zoom of the transitory of Fig. 15. (a) Grid voltages. (b) Detected angle. (c) Detected frequency. (d) Error in the detected frequency. (e) $d q$ synchronized variables in the PLL. (f) positive sequence.

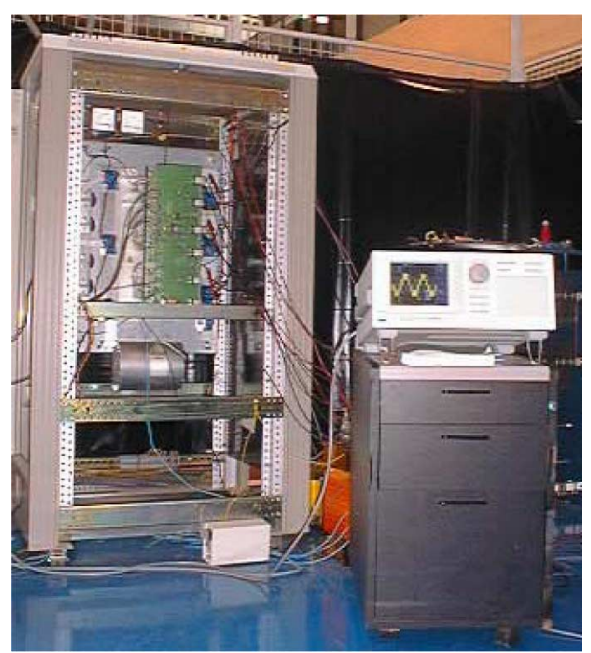

Fig. 17. Grid-connected NPC converter.

of the harmonics, the short- and fixed-response time in all the cases except in the presence of frequency variations because of the short delay of the frequency detector, and the capacity to withstand very high distorted conditions. Additionally, the effect of the perturbations in the proposed detector is always the same irrespective of the exact moment of appearance and the same tuning parameters are optimum for every disturbance.

\section{EXPERIMENTAL RESULTS}

The proposed algorithm was programmed in a DSP board TMS320F2812 and a number of experimental results were obtained. A three-phase generator CMC-156 from Omicron was used to provide the grid voltages. All the tests were performed

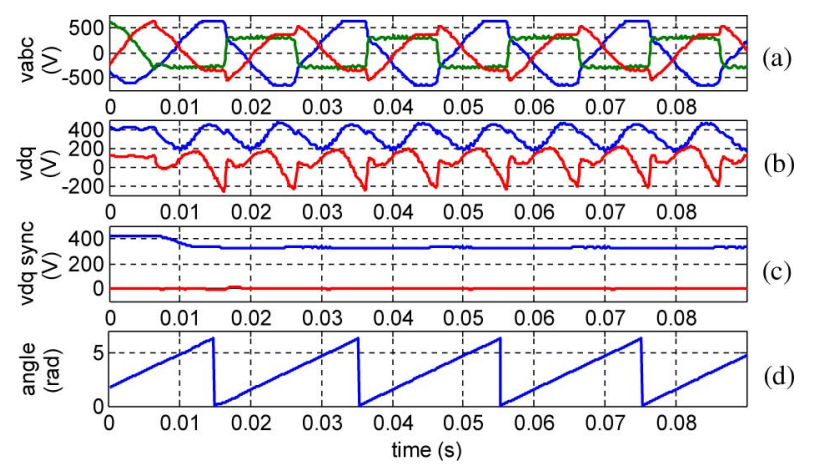

Fig. 18. Experimental results. Real unbalance and distortion. (a) Grid voltages (b) $d q$ components before the MAF. (c) $d q$ synchronized variables in the PLL (d) Detected angle.

with a line-to-neutral voltage of $50 \mathrm{Vrms}$ at $50 \mathrm{~Hz}$ except other values specified.

Fig. 14 displays the main variables of the proposed FSPLL. The grid frequency is maintained constant at $50 \mathrm{~Hz}$ throughout the process. An abrupt short circuit occurs at $t=60 \mathrm{~ms}$ (a 100\% single-phase voltage dip). At $t=140 \mathrm{~ms}$, the previous voltage dip recovers and a three-phase $70 \%$ voltage dip, as well as an odd harmonic set is introduced as follows. Up to the 25th harmonic according to $V_{h}=V_{\text {fundamental }} / h$ for $h=3,5, \ldots, 25$. The variability of the extracted frequency around the real frequency at $50 \mathrm{~Hz}$ is shown. The sampling frequency is $10 \mathrm{kHz}$, thus, $50 \mathrm{~Hz}$ would suppose 200 samples/period. The measure oscillates between two samples ( 200 samples \pm 1 when the frequency is fixed at $50 \mathrm{~Hz}$ ). Observe the fast detection of the fundamental amplitude change. There is no change in the positivesequence phase during this process, as the detected angle shows. Thus, the frequency and angle are detected accurately, showing a good performance in the presence of voltage dips and high harmonic distortion.

The experimental test of Fig. 15 shows the performance of the variable-frequency FSPLL when the input voltage has a timevarying frequency. The error in the detected frequency is also shown for a better clarity. The input frequency starts at $50 \mathrm{~Hz}$. At $t=250 \mathrm{~ms}$, it starts to vary at $10 \mathrm{~Hz} / \mathrm{s}$ up to $59 \mathrm{~Hz}$. In addition, a single-phase voltage dip of $30 \%$ occurs at $t=500 \mathrm{~ms}$ until the end. Fig. 16 shows a zoom of the transitory. Note that even in the presence of such adverse operating conditions, the proposed positive-sequence detector is able to detect the angle correctly and the $d q$ components are synchronized perfectly.

The proposed FSPLL has been used in a real application to connect an neutral point clamped (NPC) converter to a $400 \mathrm{~V}$ grid, as shown in Fig. 17. The system has been subjected to a hard distortion in the test of Fig. 18. Observe that even under such a pessimistic scenario, the high distortion of the positive sequence $d q$ components is removed and an accurate detection of the angle is performed.

\section{CONCLUSION}

In this paper, a new PLL has been presented for positivesequence detection in a three-phase system. The structure is based on a MAF that guarantees complete cancellation of the 
effects produced by grid voltage imbalances and harmonics on the detected variables. Moreover, the parameters of the PI controllers are tuned to achieve a wide closed-loop bandwidth, thus, the dynamic response of the system is improved significantly. This is possible because unwanted oscillations have been removed in a previous stage. Simulation and experimental results have been presented, which verify good performance of the system in the presence of harmonics, imbalances, and phase changes in the grid voltages. Performance of the presented PLL has proved considerably better than the basic PLL design. In addition, it shows clear advantages in the presence of harmonics over the newest and more sophisticated positive-sequence detectors. On the other hand, it has a similar dynamic response and behavior in the presence of voltage dips. A remarkable advantage of the proposed system is its simplicity compared to those with a similar performance. Furthermore, the PLL includes a simplefrequency detector that makes it frequency adaptive. This guarantees its proper operation even under large frequency changes.

\section{REFERENCES}

[1] M. Cirrincione, M. Pucci, G. Vitale, and A. Miraoui, "Current harmonic compensation by a single-phase shunt active power filter controlled by adaptive neural filtering," IEEE Trans. Ind. Electron., vol. 56, no. 8, pp. 3128-3143, Aug. 2009.

[2] K. H. Kwan, Y. C. Chu, and P. L. So, "Model-based H-infinity control of a unified power quality conditioner," IEEE Trans. Ind. Electron., vol. 56, no. 7, pp. 2493-2504, Jul. 2009.

[3] C.A. Busada, H. G. Chiacchiarini, and J. C. Balda, "Synthesis of sinusoidal waveform references synchronized with periodic signals," IEEE Trans. Power Electron., vol. 23, no. 2, pp. 581-590, Mar. 2008.

[4] A. Pigazo, V. M. Moreno, and E. J. Estebanez, "A recursive Park transformation to improve the performance of synchronous reference frame controllers in shunt active power filters," IEEE Trans. Power Electron., vol. 24, no. 9, pp. 2065-2075, Sep. 2009.

[5] M. Dai, M. N. Marwali, J.-W. Jung, and A. Keyhani, "Power flow control of a single distributed generation unit," IEEE Trans. Power Electron., vol. 23, no. 1, pp. 343-352, Jan. 2008.

[6] M. Silva, B. M. Lopes, B. J. C. Filho, R. P. Campana, and W. C. Bosventura, "Performance evaluation of PLL algorithms for singlephase grid-connected systems," in Proc. Ind. Appl. Conf. Annu. Meeting 2004, Oct., vol. 4, pp. 2259-2263.

[7] M. Karimi-Ghartemani and M. Reza Iravani, "A nonlinear adaptive filter for online signal analysis in power systems: Applications," IEEE Trans. Power Del., vol. 17, no. 2, pp. 617-622, Apr. 2002.

[8] M. Karimi-Ghartemani, H. Karimi, and M. Reza Iravani, "A magnitude/phase-locked loop system based on estimation of frequency and in-phase/quadrature-phase amplitudes," IEEE Trans. Ind. Electron., vol. 51, no. 2, pp. 511-517, Apr. 2004.

[9] T. Thacker, R. Wang, D. Dong, R. Burgos, F. Wang, and D. Boroyevich, "Phase-locked loops using state variable feedback for single-phase converter systems," in Proc. APEC2009, Washington, DC, Feb. 15-19, pp. 864-870.

[10] R. M. Santos Filho, P. F. Seixas, P. C. Cortizo, L. A. B. Torres, and A. F. Souza, "Comparison of three single-phase PLL algorithms for UPS applications," IEEE Trans. Ind. Electron., vol. 55, no. 8, pp. 2923-2932, Aug. 2008.

[11] M. Ciobotaru, R. Teodorescu, and F. Blaabjerg, "A new single-phase PLL structure base on second order generalized integrator," in Proc. PESC2006, Jun., vol. 4, pp. 1-6.

[12] D. Jovcic, "Phase locked loop system for FACTS," IEEE Trans. Power Syst., vol. 18, no. 3, pp. 1116-1124, Aug. 2003.

[13] L. G. B. Barbosa, Rolim, D. R. Rodrigues, and da Costa, Jr, M. Aredes, "Analysis and software implementation of a robust synchronizing PLL circuit based on the pq theory," IEEE Trans. Ind. Electron., vol. 53, no. 6 , pp. 1919-1926, Dec. 2006.

[14] S.-K. Chung, "A phase tracking system for three phase utility interface inverters," IEEE Trans. Power Electron., vol. 15, no. 3, pp. 431-438, May 2000.
[15] P. Rodríguez, J. Pou, J. Bergas, J. I. Candela, R. Burgos, and D. Boroyevich, "Decoupled double synchronous reference frame PLL for power converters control," IEEE Trans. Power Electron., vol. 22, no. 2, pp. 584-592, Mar. 2007

[16] P. Xiao, K. A. Corzine, and G. K. Venayagamoorthy, "Multiple reference frame-based control of three-phase PWM boost rectifiers under unbalanced and distorted input conditions," IEEE Trans. Power Electron., vol. 23, no. 4, pp. 2006-2017, Jul. 2008.

[17] J. Pou, E. Robles, S. Ceballos, J. Zaragoza, A. Arias, and P. Ibáñez, "Control of back-to-back-connected neutral-point-clamped converters in wind mill applications," presented at the EPE2007, Dresden, Denmark, Sep. 2-5.

[18] S. Alepuz, S. Busquets, J. Bordonau, J. Pontt, C. Silva, and J. Rodríguez, "Fast on-line symmetrical components separation method for synchronization and control purposes in three phase distributed power generation systems," presented at the EPE2007, Dresden, Denmark, Sep. 2-5.

[19] M. Karimi-Ghartemani and M. Reza Iravani, "A method for synchronization of power electronic converters in polluted and variable-frequency environments," IEEE Trans. Power Syst., vol. 19, no. 3, pp. 1263-1270, Aug. 2004

[20] S. Alepuz, S. Busquets-Monge, J. Bordonau, A. Martinez-Velasco, C. Silva, J. Pontt, and J. Rodriguez, "Control strategies based on symmetrical components for grid-connected converters under voltage dips," IEEE Trans. Ind. Electron., vol. 56, no. 6, pp. 2162-2173, Jun. 2009.

[21] P. Rodríguez, A. Luna, M. Ciobotaru, R. Teodorescu, and F. Blaabjerg, "Advanced grid synchronization system for power converters under unbalanced and distorted operating conditions," in Proc. IEEE IECON2006, Paris, France, Nov. 7-10, pp. 5173-5178.

[22] D. Yazdani, M. Mojiri, A. Bakhshai, and G. Joós, "A fast and accurate synchronization technique for extraction of symmetrical components," IEEE Trans. Power Electron., vol. 24, no. 3, pp. 674-684, Mar. 2009.

[23] D. Yazdani, A. Bakhshai, and P. K. Jain, "Grid synchronization techniques for converter interfaced distributed generation systems," in Proc. IEEE ECCE 2009, Sep. 20-24, pp. 2007-2014.

[24] P. Rodriguez, R. Teodorescu, I. Candela, A. V. Timbus, M. Liserre, and F. Blaabjerg, "New positive-sequence voltage detector for grid synchronization of power converters under faulty grid conditions," in Proc. IEEE PESC2006, Jeju, South Korea, Jun. 18-22, pp. 1-7.

[25] H. E. P. Souza, F. Bradaschia, F. A. S. Neves, M. C. Cavalcanti, G. M S. Azevedo, and J. P. Arruda, "A method for extracting the fundamental frequency positive-sequence voltage vector based on simple mathematical transformations," IEEE Trans. Ind. Electron., vol. 56, no. 5, pp. 15391547, May 2009

[26] R. F. de Camargo and H. Pinheiro, "Synchronisation method for threephase PWM converters under unbalanced and distorted grid," IEE Proc. Electr. Power Appl., vol. 153, no. 5, pp. 763-772, Sep. 2006.

[27] H. S. Timorabadi and F. P. Dawson, "A three-phase frequency adaptive digital phase locked loop for measurement, control, and protection in power systems," in Proc. IEEE PCC2007, Nagoya, Japan, Apr. 2-5, pp. $183-190$.

[28] A. Ghoshal and V. John, "A Method to Improve PLL Performance under abnormal grid conditions," presented at the NPEC2007, Indian Institute of Science, Bangalore, India, Dec. 17-19.

[29] E. Robles, S. Ceballos, J. Pou, J. Zaragoza, and I. Gabiola, "Grid synchronization method based on a quasi-ideal low-pass filter stage and a phase-locked loop," in Proc. IEEE PESC2008, Rhodes, Greece, Jun. 1519, pp. 4056-4061.

[30] F. D. Freijedo, J. Doval-Gandoy, O. Lopez, and E. Acha, "A generic openloop algorithm for three-phase grid voltage/current synchronization with particular reference to phase, frequency, and amplitude estimation," IEEE Trans. Power Electron., vol. 24, no. 1, pp. 94-107, Jan. 2009.

[31] E. Robles, J. Pou, S. Ceballos, I. Gabiola, and M. Santos, "Grid sequence detector based on a stationary reference frame," presented at the Eur. Conf. Power Electron. Appl., Barcelona, Spain, Sep. 8-10. 2009.

[32] L. Asnin, V. Backmutsky, and M. Gankin, "Comparative characteristics of main methods for dynamic estimation of frequency and magnitude parameters in power systems," in Proc. 22nd Conv. Electr. Electron. Eng., Dec.1, 2002, pp. 35-38.

[33] L. Asnin, V. Backmutsky, M. Gankin, J. Blashka, and M. Sedlachek, "DSP methods for dynamic estimation of frequency and magnitude parameters in power system transients," presented at the Power Tech 2008, vol. 4, Porto, Portugal, Sep. 10-13.

[34] O. Vainio and S. J. Ovaska, "Digital filtering for robust $50 / 60 \mathrm{~Hz}$ zerocrossing detectors," IEEE Trans. Instrum. Meas., vol. 45, no. 2, pp. 426430, Apr. 1996 
[35] O. Vainio and S. J. Ovaska, "Noise reduction in zero crossing detection by predictive digital filtering," IEEE Trans. Ind. Electron., vol. 42, no. 1, pp. 58-62, Feb. 1995

[36] M. B. Duric and Z. R. Durisic, "Frequency measurement in power networks in the presence of harmonics using fourier and zero crossing technique," in Proc. Power Tech 2005, St. Petersburg, Russia, Jun. 27-30, pp. $1-6$.

[37] M. M. Begovic, P. M. Djuric, S. Dunlap, and A. G. Phadke, "Frequency tracking in power networks in the presence of harmonics," IEEE Trans. Power Del., vol. 8, no. 2, pp. 480-486, Apr. 1993.

[38] D. W. P. Thomas and M. S. Woolfson, "Evaluation of frequency tracking methods," IEEE Trans. Power Del., vol. 16, no. 3, pp. 367-371, Jul. 2001.

[39] M. Sanaye-Pasand and V. J. Marandi, "Frequency estimation of distorted signals for control and protection of power system," in Proc. 8th IEE Int. Conf. Dev. Power Syst. Protection, Amsterdam, The Netherlands, Apr. 5-8, 2004, pp. 631-634.

[40] H. K. Kwok and D. L. Jones, "Improved instantaneous frequency estimation using an adaptive short-time fourier transform," IEEE Trans. Signal Process., vol. 48, no. 10, pp. 2964-2972, Oct. 2000.

[41] J. Yang and C. Liu, "A precise calculation of power system frequency," IEEE Trans. Power Del., vol. 16, no. 3, pp. 361-366, Jul. 2001.

[42] A. Routray, A. K. Pradhan, and K. P. Rao, "A novel Kalman filter for frequency estimation of distorted signals in power systems," IEEE Trans. Instrum. Meas., vol. 51, no. 3, pp. 469-479, Jun. 2002.

[43] H. Karimi, M. Karimi-Ghartemani, and M. R. Iravani, "Estimation of frequency and its rate of change for applications in power systems," IEEE Trans. Power Del., vol. 19, no. 2, pp. 472-480, Apr. 2004.

[44] M. Mojiri, M. Karimi-Ghartemani, and A. Bakhshai, "Estimation of power system frequency using an adaptive notch filter," IEEE Trans. Instrum. Meas., vol. 56, no. 6, pp. 2470-2477, Dec. 2007.

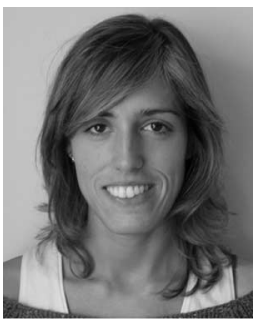

Eider Robles was born in Bilbao, Spain, in 1980. She received the M.S. degree in electronic and automatic engineering from the University of Deusto, Bilbao, in 2003. She is currently working toward the Ph.D. degree in the Department of Electronic Engineering, University of the Basque Country, Bilbao.

Since 2003, she has been with the RobotikerTecnalia Research Centre, Zamudio, Spain, where she is currently a Research Engineer in the Energy Unit. She is author or coauthor of more than 20 technical papers. Her research interests include the grid connection and control of synchronous wind turbines with multilevel converters.

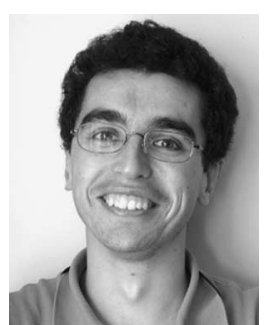

Salvador Ceballos received the B.Sc degree in physics from the University of Cantabria, Santander, Spain, in 2001, and the B.Eng. and Ph.D. degrees in electronic engineering from the University of the Basque Country, Bilbao, Spain, in 2002 and 2008, respectively.

Since 2002, he has been with the RobotikerTecnalia Research Centre, Zamudio, Spain, where he is currently a Development Engineer in the Energy Unit. From May 2008 to May 2009, he was a Visiting Researcher at the Hydraulic and Maritime Research Centre, University College Cork, Cork, Ireland. He has authored or coauthored more than 30 published technical papers. His research interests include multilevel converters, fault-tolerant power electronic topologies, and renewable energy systems.

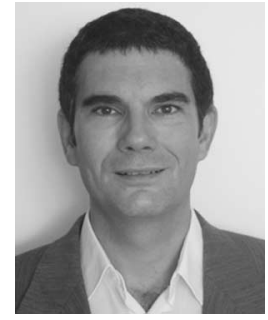

Josep Pou (S'97-A'02-M'03) received the B.S., M.S., and Ph.D. degrees in electrical engineering from the Technical University of Catalonia (UPC), Terrassa, Spain, in 1989, 1996, and 2002, respectively.

During 1989, he was the Technical Director of Polylux S.A. In 1990, he joined as an Assistant Professor with the Faculty of UPC, where he became an Associate Professor in 1993. From February 2001 to January 2002, and from February 2005 to January 2006, he was a Researcher in the Center for Power Electronics Systems, Virginia Polytechnic Institute and State University (Virginia Tech), Blacksburg, VA. He has authored or coauthored more than 80 published technical papers. He has been involved in several industrial projects and educational programs in the fields of power electronics and systems. His research interests include modeling and control of power converters, multilevel converters, power quality, renewable energy systems, and motor drives.

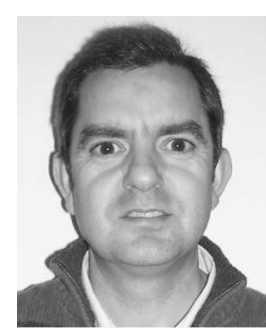

José Luis Martín (M'97) received the M.S. and $\mathrm{Ph} . \mathrm{D}$. degrees in electrical engineering from the University of the Basque Country, Bilbao, Spain, in 1988 and 1992, respectively.

From 1989 to 1995, he was an Assistant Professor of electronic technology in the Electronics and Telecommunications Department, University of the Basque Country, where he became an Associate Professor in 1995, and the Head of the Electronics and Telecommunications Department from 1995 to 2001. From 2001 to 2005, he was a Vice-Dean of the Faculty of Engineering, Bilbao. He has been involved with the Applied Electronics Research Team of the University of the Basque Country.

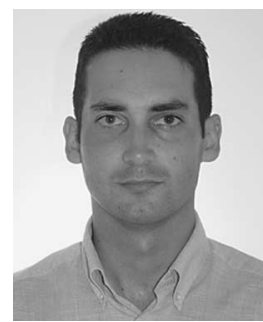

Jordi Zaragoza (S'08) received the B.S. degree in electronic engineering and the M.S. degree in automatic and electronic industrial engineering from the Technical University of Catalonia (UPC), Terrassa, Spain, in 2001 and 2004, respectively, where he is currently working toward the Ph.D. degree in the Terrassa Industrial Electronic Group, Department of Electronic Engineering.

In 2003, he was an Assistant Professor at UPC From September 2006 to September 2007, he was a Researcher with the Energy Unit, Robotiker-Tecnalia Research Centre, Zamudio, Spain. He has authored or coauthored more than 20 published technical papers. His current research interests include modeling and control of power converters, multilevel converters, wind energy, and power quality.

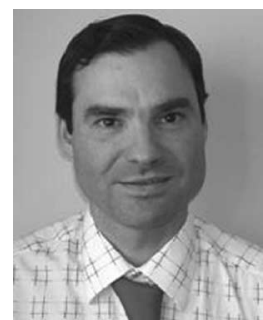

Pedro Ibañez (M'04) was born in Bilbao, Spain, in 1964. He received the M.Sc. and Ph.D. degree in electrical engineering from the University of Basque Country, Bilbao, in 1988 and 1991, respectively.

From 1988 to 1997, he was an Assistant Professor of electronic technology in the Electronics and Telecommunications Department, University of Basque Country, where he became an Associate Professor in 1997. Since 1992, he has been with Robotiker-Tecnalia Research Centre, Zamudio, Spain, where he is currently the Technology Director of the Energy Unit. He has been engaged in many projects related to electronics systems, digital control systems, and power converters for energy applications. He has been involved in more than 30 research projects supported by public institutions (included EU) and private companies. He is the author or coauthor of more than 30 technical papers. 